\title{
IMPROVEMENT AND PERFORMANCE EVALUATION OF A SYSTEM FOR MONITORING ROTATIONS AND DISPLACEMENTS OF BRIDGES BASED ON LASER POINTER AND DIGITAL PHOTOGRAMMETRY
}

\author{
G. Artese ${ }^{1, *}$ \\ ${ }^{1}$ Department of Civil Engineering, University of Calabria, Via Bucci cubo 45 B, 87036 Rende, Italy - g.artese@unical.it
}

Technical Commission II

KEY WORDS: Laser Pointer, Digital Photogrammetry, Image Processing, Structure Monitoring.

\begin{abstract}
:
A system for monitoring rotations and displacements of bridges based on laser pointer and digital photogrammetry is described. The system uses three common laser pointers and image processing. The inclination of the elastic line is measured by analysing the individual frames of an HD video of the laser beam footprint projected onto a flat target. The methodology, able to conjugate a high precision, low cost, and easiness of use, is an evolution of a method developed at University of Calabria, Italy. The use of three laser pointers allows to improve the performance of the previous method, obtaining both displacements and rotations at a generic point of the bridge deck, and deriving the transverse rotation of the deck cross section. The investigated method exploits the laser pointers' property to provide a steady pointing direction, a long-range and a high-brightness visible imprint. The method and the results of an experimental test are described and discussed.
\end{abstract}

\section{INTRODUCTION}

To evaluate the health status of a bridge and to verify its bearing capacity, inclination and vertical displacements of the deck are among the most important technical parameters to measure. Structural rotations and displacements can be monitored using several methods, both conventional and innovative. However, it is still a difficult challenge to implement a system that can, at the same time, enable precision, automation, static and dynamic monitoring without using high-cost tools.

The load tests for checking the state of health of a bridge are usually carried out by charging the deck with static loads, generally obtained by parking heavy trucks in known positions. The measurements of vertical displacements are carried out by spirit levels or total stations (Lantsoght, 2017).

Nowadays, Structural Health Monitoring (SHM) is performed by acquiring several physical and mechanical parameters (Zinno et al., 2019). Among these, we can list: (a) structural vibrations, among which we can distinguish natural frequency, mode shape and other modal parameters (Fan, Qiao, 2011); (b) strain, measured by strain-gauges wired or wireless; (c) inclinations, obtained by inclinometers.

Recently, integrated tools have been proposed, which can be configured in a wireless network and managed remotely (Artese G. et al., 2015a).

Focusing attention on the techniques used to measure movements, we recall: (a) digital levels: (b) total stations, also remotely managed (Artese G. et al., 2015b; Artese, S. and Perrelli, M., 2018); (c) dial gauges; (d) GNSS receivers; (e) terrestrial laser scanning (TLS); (f) digital photogrammetry; (g) radar interferometry both satellite (Artese G. et al., 2016) and ground based (Di Pasquale et al., 2018). TLS and digital photogrammetry are successfully used also for dynamic measurements (Artese, S., 2019, Yoneyama, Ueda, 2012, Kwak et al., 2013, Lu et al., 2016).
We should also underline the recent use of Micro ElectroMechanical Systems (MEMS) based inclinometers, for getting deflection measurements ( $\mathrm{Yu}$ et al., 2013). The high $\mathrm{S} / \mathrm{N}$ ratio of these acquisitions limits their usability to static measurements.

With reference to the early use of a laser beam to measure deflections, we can mention the system described in (Tang and $\mathrm{Li}, 2008)$

In the last years, we can observe an increase in methods based on laser projection sensing, probably due to the availability of low-cost hardware (Jeon et al., 2011, Park et al., 2010, Lee et al., 2012).

The methodology described in the following, able to conjugate a high precision, low cost, and easiness of use, has been set up in this context. By detecting the variation of the tangent to the elastic line of the deck, the inclination is obtained. The tangent to the elastic line is materialized by the laser beam of a laser pointer, fixed to a point of the deck structure. The beam is projected onto a screen opportunely placed in a fixed position and at a suitable distance, thus obtaining an amplification of the laser fingerprint movement and, consequently, a more accurate result.

By analyzing the frames of a video of the laser footprint acquired during the monitoring activities, it is possible to extract the dynamic deflections.

The main characteristics of the method are: (1) Low cost; (2) Lightweight and small hardware; (3) Ease of installation; (4) Capability to achieve the required accuracy for bridge load tests.

The methodology has been developed at University of Calabria, Italy. It is an evolution of the one described in (Artese S. et al., 2018) and differs mainly in the following aspects: (1) measurements can be performed not only at the support, but at any point of the deck; (2) in the monitored points both rotation and lowering are measured, thanks to the use of two pointers; (3) it is possible to measure the transverse rotation of the deck.

\footnotetext{
* Corresponding author
} 
This paper deals with: (1) the description of the methodology; (2) the hardware components; (3) the implemented software; (4) the in-field test; and (5) the discussion of the results.

\section{MATERIALS AND METHODS}

\subsection{The Methodology}

The investigated method exploits the laser pointers' property to provide a steady pointing direction, a long-range and a highbrightness visible imprint.

By projecting a laser beam, positioned at the intrados of a bridge deck, on a plane target approximately orthogonal to the direction of the ray, the footprint will undergo a displacement $\Delta \mathrm{H}$ due to two components: (a) the lowering or raising of the laser source and (b) the variation of the laser beam inclination. Both components are linked to the movements and inclinations of the structure to which the laser source is locked (Figure 1).

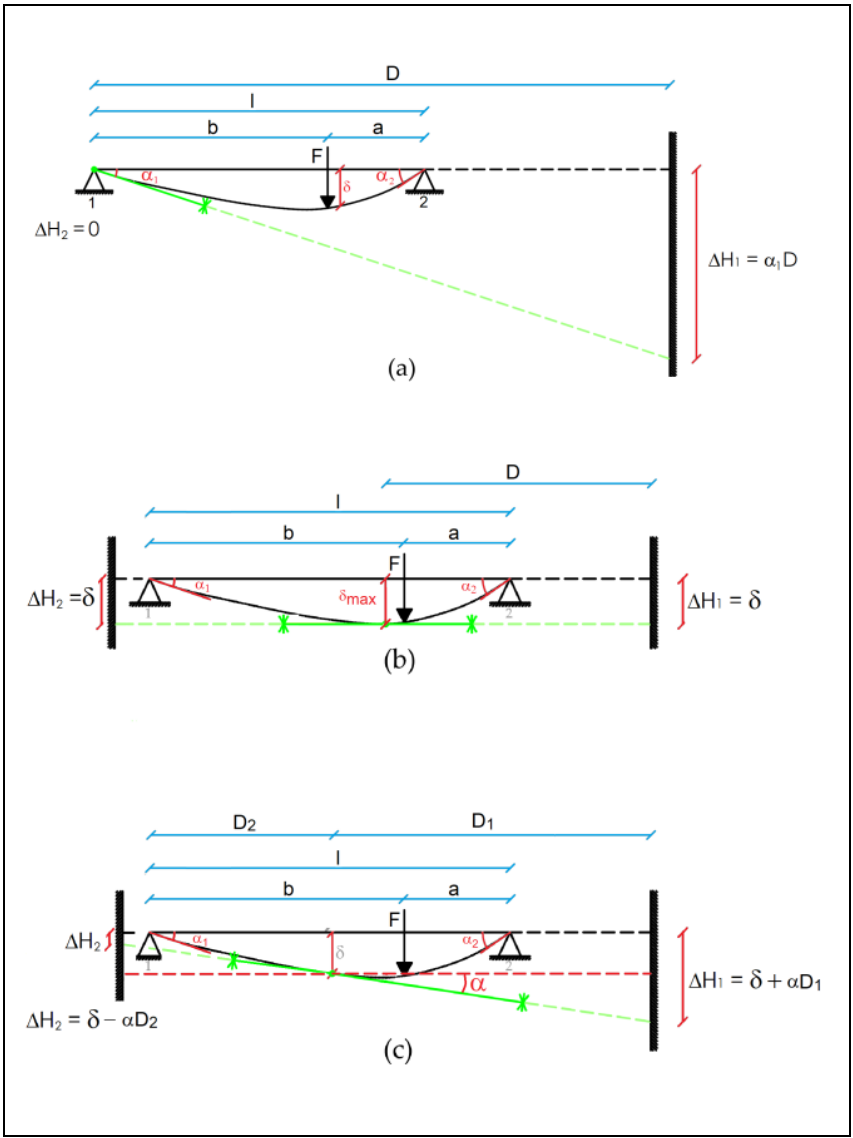

Figure 1. The displacement of the laser footprints: (a) with the pointer subject just to inclination (fixed to the end of the span); (b) with the pointers positioned in the maximum displacement point (with lowering only); (c) with the laser pointers fixed on a point subject to both inclination and lowering.

The component (a) produces a shift $\delta$ of the laser footprint equal to the displacement of the laser source. The component (b) causes a displacement $\alpha \mathrm{D}$ proportional to the distance $\mathrm{D}$ between the laser source and the target. It is therefore possible to greatly amplify this displacement by positioning the target at a convenient range; this allows one to obtain the tilt variation with remarkable precision.

With reference to Figure 1c, let consider two laser pointers, fixed in the same position and orientated in opposite directions.
The displacement of the laser beam footprint on the right side is:

$$
\Delta \mathrm{H}_{1}=\delta+\tan \alpha \mathrm{D}_{1}
$$

The displacement of the laser beam footprint on the left side is:

$$
\Delta \mathrm{H}_{2}=\delta-\tan \alpha \mathrm{D}_{2}
$$

Where:

$\delta=$ the displacement of the monitored point;

$\Delta \mathrm{H}_{1}=$ displacement of the laser footprint on the target 1;

$\Delta \mathrm{H}_{2}=$ displacement of the laser footprint on the target 2;

$\alpha=$ laser beam inclination;

$\mathrm{D}_{1}=$ distance from monitored point to target 1 ;

$\mathrm{D}_{2}=$ distance from monitored point to target 2 .

From the equations 1,2 one can derive the inclination $\alpha$ (equation 3 ) and the displacement $\delta$ (equation 4 ).

$$
\begin{gathered}
\tan \alpha=\left(\Delta \mathrm{H}_{1}+\Delta \mathrm{H}_{2}\right) /\left(\mathrm{D}_{1}+\mathrm{D}_{2}\right) \\
\delta=\Delta \mathrm{H}_{1}-\left[\left(\Delta \mathrm{H}_{1}+\Delta \mathrm{H}_{2}\right) /\left(\mathrm{D}_{1}+\mathrm{D}_{2}\right)\right] \mathrm{D}_{1}
\end{gathered}
$$

By positioning two laser pointers on the right and left sides of the deck section, that aim at the same targets, it is possible to obtain the displacements difference between the right and left sides of the same transverse cross section and, therefore, the transverse rotation of the deck (Figure 2).

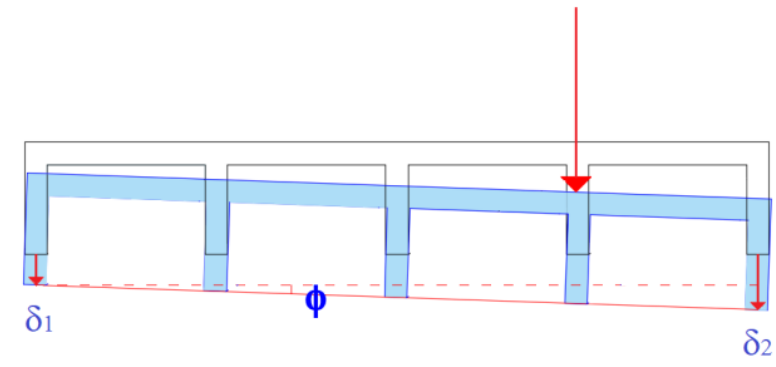

Figure 2. The displacements difference between the displacements $\delta_{1}$ and $\delta_{2}$ allows to obtain the transverse rotation $\phi$ of the deck.

During the monitoring activities, a video of the laser footprint oscillations is acquired. The elaboration of the images of the single frames allows to detect the variable position of the centroid of the laser footprint. In this way inclination variations and dynamic deviations can be obtained.

In the case of a mobile load, synchronizing the video of the footprints with a video recording of the bridge deck makes it possible to relate the position of the load and the deformations / inclinations.

\subsection{The Hardware Components}

The hardware components are: (a) three laser pointers; (b) two cameras for laser footprint video capturing; and (c) a computer.

\subsubsection{The Laser Pointers}

Three SCITOWER SCT306-532 nm laser pointers were used, mounted on a MTOLASER $21 \mathrm{~mm}$ three axis adjustable laser pointer module holder, fixed to a Holmarc switchable magnetic 
post basis model MB - 50 (Figure 3). The main characteristics are shown in Table 1.

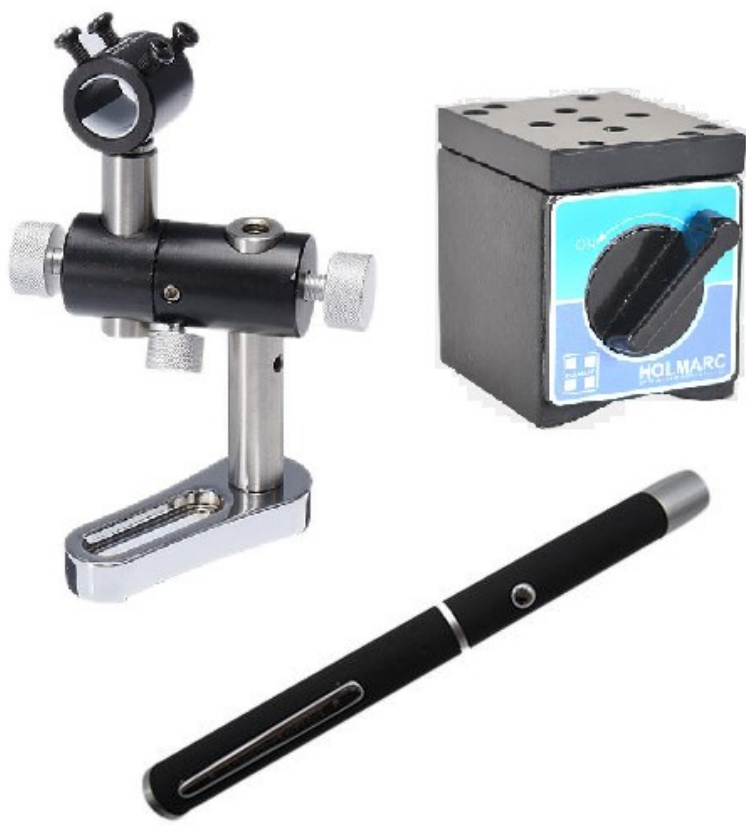

Figure 3. The laser pointer, the three axis adjustable laser pointer module holder, and the switchable magnetic post basis

\begin{tabular}{|c|c|}
\hline Feature & Value \\
\hline Wavelength & $532 \pm 0.1 \mathrm{~nm}($ Green $)$ \\
\hline Beam diameter & $2.0 \mathrm{~mm}$ \\
\hline Beam divergence & $0.8 \mathrm{mrad}$ \\
\hline Power & $100 \mathrm{~mW}($ Gaussian Beam $)$ \\
\hline Pointing stability & $<0.05 \mathrm{mrad}$ \\
\hline Beam spot roundness & $\geqq 90 \%$ \\
\hline
\end{tabular}

Table 1. Characteristics of the laser pointer.

\subsubsection{The Cameras}

The video of the laser footprints were acquired using two Xiaomi YI 4K Action Cameras. The main characteristics are shown in Table 2.

\begin{tabular}{|l|l|}
\hline \multicolumn{1}{|c|}{ Feature } & \multicolumn{1}{|c|}{ Value } \\
\hline Type & Xiaomi YI 4K Action Camera \\
\hline Video resolution & $3840 \times 2160$ Pixel at 30 fps \\
\hline Max frame rate & $200 \mathrm{fps}$ \\
\hline File format & $\begin{array}{l}\text { NEF (RAW), JPEG, NEF } \\
\text { (RAW)+JPEG }\end{array}$ \\
\hline Lens & $\begin{array}{l}\text { f/2.8 aperture, 3.2mm focal length, } \\
\text { glass, 145-degrees wide-angle lens. }\end{array}$ \\
\hline Sensor & $\begin{array}{l}\text { 8 MP Sony IMX317 } \\
\text { Size (Diagonal) } 7.2 \mathrm{~mm}\end{array}$ \\
\hline Pixel Size & 1.62 micron \\
\hline
\end{tabular}

Table 2. Characteristics of the Xiaomi YI 4K digital camera.

\subsubsection{The Computer}

A Dell XPS 139360 Notebook was used. The CPU is an Intel Core i7-7500U with a $2.7 \mathrm{GHz}$ clock and 8 GB DDR SDRAM. The notebook is provided with a 256 GB SSD hard disk, a 13.3 inch Full HD display, and a graphic card Intel HD 620. The operating system is Windows 10 Pro.

\subsection{The Software Implemented}

As for the software, a program was developed in Matlab ${ }^{\circledR}$ for the determination of the laser footprint centroids projected on each flat target. The program uses the calibration parameters of the digital camera.

With regard to the mean scale of the frame, the Ground Sample Distance (GSD) of $0.2 \mathrm{~mm}$ has been chosen, in order to obtain the required precision of the measurements. To this end, a 40 $\mathrm{cm}$ camera-target distance was used. The target is a rigid plastic board with a glued graph paper.

The code developed is based on the one described in (Artese et al., 2018). In the present version two laser footprints must be detected, given that the laser beams coming from the right and the left sides of the same transverse cross section are pointed to the same target.

\section{RESULTS AND DISCUSSION}

\subsection{The Test}

The test was carried out on a bridge at the University of Calabria, Italy. It is a double deck bridge: the upper deck can be used for vehicular traffic, while the lower one is reserved for pedestrians. The laser pointers were fixed to two plates used for hanging the pedestrian deck (Figures 4, 5).

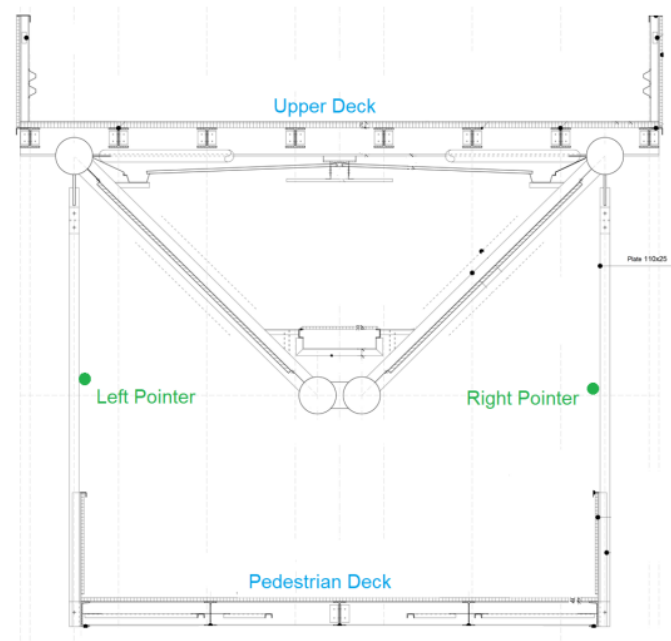

Figure 4. Cross section of the bridge deck. The laser pointers are fixed to the plates used to hang the pedestrian deck.

The load used for the test was a heavy truck, with a weight of about $250 \mathrm{kN}$, positioned at the middle of the central span. The laser pointers were positioned at a distance of $88.58 \mathrm{~m}$ from the southern target and of $104.17 \mathrm{~m}$ from the northern one. The eccentricity was $1.5 \mathrm{~m}$ respect to the longitudinal axis. With reference to Figure 4, on the east side of the cross section (right) two pointers were positioned, while on the west side only one laser pointer was positioned, pointing to the northern target, used for obtaining the transverse rotation. 

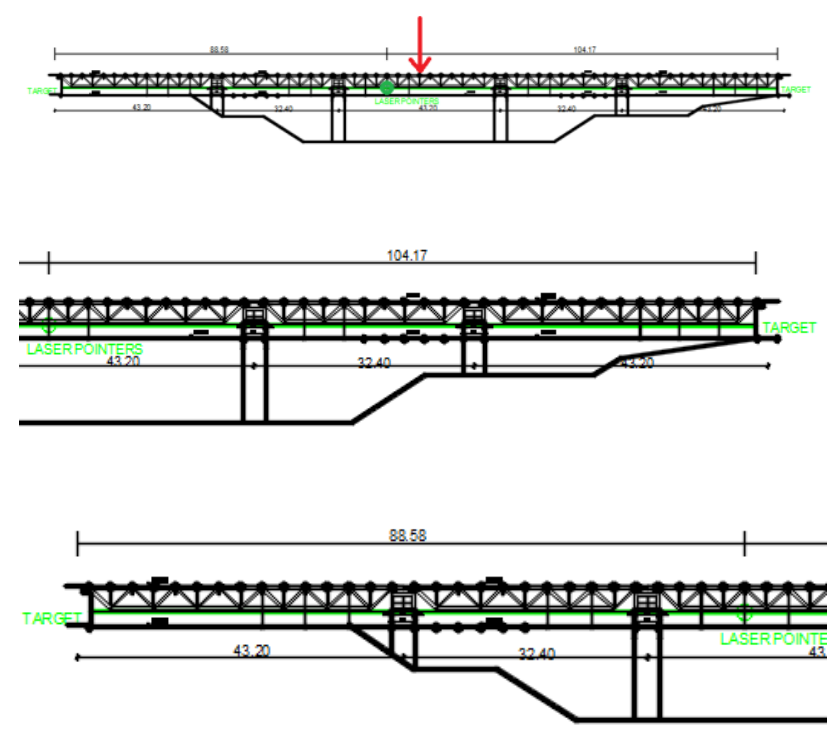

Figure 5. Test layout (top). Enlargement of the north (central panel) and of the south stretch (lower panel).
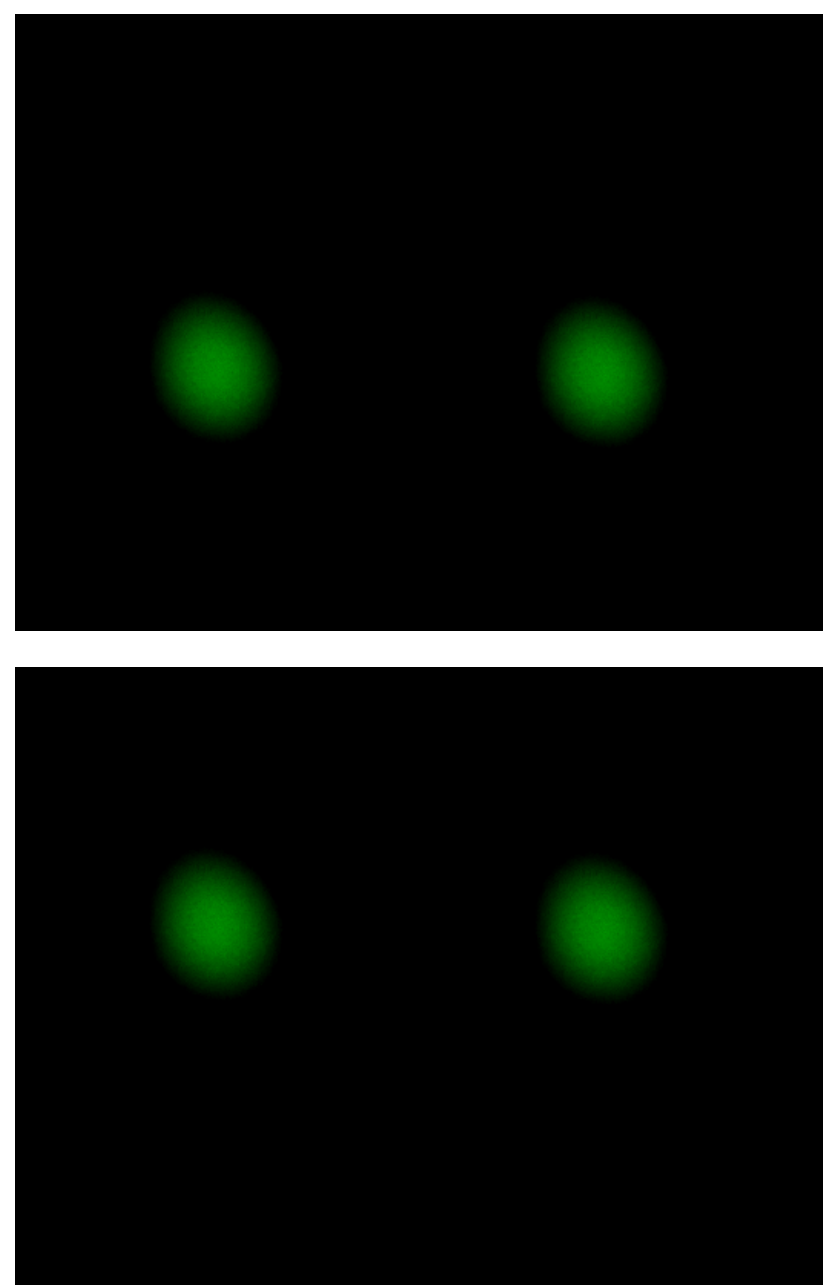

Figure 6. Enlargements of two frames obtained for the northern target at the beginning (top) and at the end of the test (bottom panel). The left and right footprints are generated by the left and by the right pointers, respectively.
In Figure 6, we can observe two frames obtained at the beginning and at the end of the test by filming the northern panel. The limitation of ISO sensitivity and of the iris allowed to obtain a well defined shape of the laser beam footprints, thus determining accurately the centroids. The frames were processed using the above described code in Matlab ${ }^{\circledR}$. The positions of the centroids were obtained in pixel coordinates (rows, columns). The coordinates were obtained with a precision of .1 pixels, less than the stability of the laser beams.

\subsection{Discussion}

The results of the measurements are synthetized in Table 3. The coordinates of the centroids of the footprints, in pixels, are shown, for the pointers on the east side (right), for both the North and South targets. The measurements were carried out both with loaded bridge and unloaded bridge.

\begin{tabular}{|l|r|r|r|l|r|r|}
\hline \multirow{4}{*}{} & \multicolumn{3}{|c|}{ North Target } & \multicolumn{2}{c|}{ South Target } \\
\cline { 2 - 7 } & $\begin{array}{c}\text { Left } \\
\text { Footprint }\end{array}$ & \multicolumn{2}{c|}{$\begin{array}{c}\text { Right } \\
\text { Footprint }\end{array}$} & \multicolumn{2}{c|}{$\begin{array}{c}\text { Right } \\
\text { Footprint }\end{array}$} \\
\cline { 2 - 7 } & row & \multicolumn{1}{c|}{ col. } & \multicolumn{1}{c|}{ Row } & \multicolumn{1}{c|}{ col. } & \multicolumn{1}{c|}{ row } & \multicolumn{1}{c|}{ col. } \\
\hline Loaded bridge & 1170 & 650 & 1328 & 1925 & 1860 & 1048 \\
\hline $\begin{array}{l}\text { Unloaded } \\
\text { bridge }\end{array}$ & 1044 & 652 & 1201 & 1927 & 1937 & 1049 \\
\hline Delta (pixels) & 126 & -2 & 127 & -2 & -77 & -1 \\
\hline Delta (mm) & 25.2 & -0.4 & 25.4 & -0.4 & -15.4 & -0.2 \\
\hline
\end{tabular}

Table 3. Coordinates of the centroids of footprints. The values are in pixels except for the bottom row.

We observe a rise in the footprint on the northern target of 127 pixels, equal to $25.4 \mathrm{~mm}$. On the south target, there is a lowering of 77 pixels, equal to $-15.4 \mathrm{~mm}$.

By applying formulas 3 and 4, an inclination variation of 0.210 $\mathrm{mrad}$ and a $3.2 \mathrm{~mm}$ displacement are obtained at the laser pointers. These values are in line with those obtained using a Finite Element Method code.

As for the left pointer, the footprint on the north target undergoes a rising almost equal to that of the right pointer, being the difference of one pixel. This value, corresponding to $0.2 \mathrm{~mm}$, is less than the measurement uncertainty. The small eccentricity of the load, moreover, did not produce significant rotations of the deck. In the future, it is planned to perform a test in the presence of more significant rotations.

\section{REFERENCES}

Artese, G., Perrelli, M., Artese, S., Meduri, S., Brogno, N., 2015a. POIS, a Low Cost Tilt and Position Sensor: Design and First Tests, Sensors, 15, 10806-10824, doi:10.3390/s150510806.

Artese, G., Perrelli, M., Artese, S., Manieri F., 2015b. Geomatics activities for monitoring the large landslide of Maierato, Italy, Appl Geomat, 7: 171-188. https://doi.org/10.1007/s12518-014-0146-8.

Artese, G., Fiaschi, S., Di Martire, D., Tessitore, S., Fabris, M., Achilli, V., Ahmed, A., Borgstrom, S., Calcaterra, D., Ramondini, M., Artese, S., Floris, M., Menin, A., Monego, M., and Siniscalchi, V., 2016. Monitoring of Land Subsidence in Ravenna Municipality using Integrated Sar - Gps Techniques: Description and first Results, Int. Arch. Photogramm. Remote 
Sens. Spatial Inf. Sci., XLI-B7, 23-28, https://doi.org/10.5194/isprs-archives-XLI-B7-23-2016, 2016

Artese, S., Perrelli, M., 2018. Monitoring a Landslide with High Accuracy by Total Station: A DTM-Based Model to Correct for the Atmospheric Effects, Geosciences, 8(2), 46, doi: https://doi.org/10.3390/geosciences8020046.

Artese, S., Achilli, V., Zinno, R., 2018. Monitoring of Bridges by a Laser Pointer: Dynamic Measurement of Support Rotations and Elastic Line Displacements: Methodology and First Test. Sensors, 18(2), 338, doi: https://doi.org/10.3390/s18020338.

Artese, S., 2019. The Survey of the San Francesco Bridge by Santiago Calatrava in Cosenza, Italy. Int. Arch. Photogramm. Remote Sens. Spatial Inf. Sci., XLII-2/W9, 33-37, https://doi.org/10.5194/isprs-archives-XLII-2-W9-33-2019.

Di Pasquale, A., Nico, G., Pitullo, A., \& Prezioso, G., 2018. Monitoring Strategies of Earth Dams by Ground-Based Radar Interferometry: How to Extract Useful Information for Seismic Risk Assessment, Sensors, 18(1), 244. doi:10.3390/s18010244.

Fan, W., Qiao, P., 2011. Vibration-based damage identification methods: A review and comparative study. Struct. Health Monit. 2011, 10, 83-111, doi:10.1177/1475921710365419.

Jeon, H., Bang, Y., Myung, H., 2011. A paired visual servoing system for 6-DOF displacement measurement of structures. Smart Mater. Struct. 2011, 20, 045019.

Kwak, E., Detchev, I., Habib, A., El-Badry, M., Hughes, C., 2013. Precise photogrammetric reconstruction using modelbased image fitting for 3D beam deformation monitoring. J. Surv. Eng. 2013, 139, 143-155, doi:10.1061/(ASCE)SU.19435428.0000105 .

Lantsoght, E.O.L., der Veen, C., Boer, A., Hordijk, D.A., 2017. State-of-the-art on load testing of concrete bridges. Eng. Struct. 2017, 150, 2312-2341, doi:10.1016/j.engstruct. 472 2017.07.050.

Lee, J.J., Ho, H.N., Lee, J.H., 2012. A vision-based dynamic rotational angle measurement system for large civil structures. Sensors 2012, 12, 7326-7336.

Lu, W., Cui, Y., Teng, J., 2016. Structural displacement and strain monitoring based on the edge detection operator. Adv. Struct. Eng. 2016, 20, 191-201,

Park, J.W., Lee, J.J., Jung, H.J., Myung, H., 2010. Vision-based displacement measurement method for high-rise building structures using partitioning approach. NDT E Int. 2010, 43, 642-647, doi:10.1016/j.ndteint.2010.06.009.

doi:10.1177/1369433216660220.

Tang, C., Li, E., 2008. The design of a laser-based digital displacement/deflection measurement system of a remote object and its calibration. In Proceedings of the SPIE 6829, Advanced Materials and Devices for Sensing and Imaging III, 68291T, Beijing, China, 24 January 2008, doi:10.1117/12.757617.

Yoneyama, S., Ueda, H., 2012. Bridge deflection measurement using digital image correlation with camera movement correction. Mater. Trans. 2012, 53, 285-290, doi:10.2320/matertrans.I-M2011843.
Yu, Y., Liu, H., Li, D., Mao, X., Ou, J., 2013. Bridge deflection measurement using wireless mems inclination sensor systems. Int. J. Smart Sens. Intell. Syst. 2013, 6, 38-57, doi:10.1.1.658.8791.

Zinno, R., Artese, S., Clausi, G., Magarò, F., Meduri, S., Miceli, A., Venneri, A., 2019: Structural Health Monitoring (SHM). The Internet of Things for Smart Urban Ecosystems, Cicirelli, F., Guerrieri, A., Mastroianni, C., Spezzano, G., Vinci, A., Eds., Springer International Publishing, pp. 225-249, doi:10.1007/978-3-319-96550-5. 